\title{
Insistir en la vida: Reseña de Chávez Mac Gregor, Helena. (2018). Insistir en la politica, Rancière y la revuelta de la estética. México: UNAM; Instituto de Investigaciones Estéticas.
}

\section{Insisting on Life: Review of Chávez Mac Gregor, Helena. (2018). Insistir en la politica, Rancière y la reouelta de la estética. México: UNAM; Instituto de Investigaciones Estéticas.}

Bily López

Universidad Autónoma de la Ciudad de MÉxico

Pensar es una peligrosa tarea. Pensar filosóficamente lo es aún más. Incluso podríamos afirmar que pensar filosóficamente es un riesgo de proporciones mayúsculas cuando la filosofía se hace de cara a problemas concretos y no sólo de cara a teorías abstractas, cuando lo que está de por medio es la vida misma y no sólo una abstracción erudita. No hay que confundirse, pensar es abstraer, teorizar, ordenar y jerarquizar, trabajar con los conceptos cuya naturaleza es intangible, pero hay varias maneras de hacerlo. La teoría se puede construir de frente a pomposos conceptos que sólo a los ortodoxos especialistas en la obra de un autor hagan sentido, o bien se construye de cara a la ignominiosa existencia, frente al dolor primigenio del absurdo y en la permanente disputa de lo político. El pensamiento de Helena Chávez Mac Gregor es del segundo tipo.

Esta cualidad, no obstante, no le quita densidad, teoricidad ni rigurosidad en el uso de su lenguaje y sus conceptos. Mucho menos lo hace quedar reducido a un mero activismo. He ahí la principal virtud del pensamiento de Helena Chávez: ser 
siempre una desgarrada confrontación con el mundo y con uno mismo, elaborada desde una compleja y rigurosa composición conceptual.

Insistir en la política. Rancière y la revuelta de la estética es una muestra generosa de lo que queremos decir. Para mostrarlo, y por tratarse del primer libro no colectivo de su autora, nos gustaría dar cuenta de los conflictos que lo habitan y los territorios que lo construyen a modo de procedencia a través de los recorridos teóricos realizados a lo largo de la trayectoria académica de su autora, pues es ahí desde donde se comprende mejor la vitalidad que conforma la obra que aquí reseńamos.

\section{II}

Los intereses teóricos de Helena Chávez Mac Gregor han estado signados por el cruce entre el arte, lo estético y lo político desde su primer trabajo recepcional. En efecto, en su primer trabajo de investigación (La experiencia del arte: Walter Benjamin y el arte de la desconfianza), podemos encontrar como preocupación fundamental de su pensamiento eso que Benjamin llamó experiencia empobrecida. Frente a la experiencia moderna y kantianamente planteada, en ese texto se examinan diferentes estrategias benjaminianas para hacer frente a esa pobreza y así poder encontrar una ampliación de la experiencia. Se trata, desde luego, de lo humano, de preguntar por aquello que somos en cuanto seres humanos, de cuáles son nuestras posibilidades y de por qué la racionalidad moderna nos es inconveniente al reducir nuestro ser al conocimiento, a la medida y al cálculo eficientista; se trata de reconocer que nuestra experiencia del mundo está reducida y empobrecida, y que por ello es necesario buscar formas de ampliarla. Desde este momento, nuestra autora es capaz de localizar -a través de Kant y Benjamin- a la experiencia como un concepto onto-estético-político desde el cual se puede pensar problemáticamente la existencia, la con-vivencia, para así poder transformarla, trastocarla. El arte aparece en este primer trabajo de una manera tímida, bajo una forma discreta; se piensa en la literatura, en la fotografía, en el cine; se habla de arte surrealista sin profundizar demasiado. Pero ya desde este momento se intuye que el arte, en la medida en que "nos enseña a contrarrestar nuestra experiencia empobrecida y reducida" (Chávez, 2004: 128), acaso ofrece una posibilidad de re-vuelta.

El siguiente trabajo recepcional de nuestra autora está marcado por el duelo, la ausencia y la pérdida; es realizado en una especie de exilio voluntario en Barcelona que le permitió a nuestra autora con-vivir y teorizar con los espectros. Se trata de un afianzamiento de las relaciones problemáticas con la política y las teorías que la recubren, pero no de la mano de pensadores como Rawls o Habermas, que piensan 
la política como un modo de acción racional, sino de autores como Rancière, Nancy y Derrida, que ante todo ponen en cuestión el funcionamiento racional de lo político. A través de una furiosa y meticulosa lectura de lo derridiano, Helena Chávez aprende a desmontar discursos y a desmontarse a sí misma, como se advierte en el epílogo con el que concluye la tesis; advierte que entre significado y significante habitan diferentes tipos de fantasmagorías que hay que aprender a detectar y a descifrar en la medida de lo posible. A través de una crítica a la metafísica de la presencia, repiensa la construcción de lo político desde la presencia fantasmal, "poniendo en duda el fundamento o la estructura que dan sentido a conceptos como los de justicia y democracia” (Chávez, 2006: 14). En esta investigación busca "plantear una experiencia con el otro que pueda ser pensada como experiencia política, una experiencia política que se base en el respeto y la responsabilidad por el otro. Una experiencia que haga visible lo invisible y que nos abra a un tiempo siempre por-venir" (2006). Se trata siempre, como vemos, de pensar el por-venir, esa categoría tan recurrente en la producción filosófica de Helena Chávez.

Por si el trabajo teórico en sí mismo no diera cuenta del intenso vitalismo del que procede, es decir, de su intrincada y problemática relación con la vivencia y la experiencia, al final de la tesis se incluye un epílogo que nos lo deja ver. Después de retratar un intenso paralelismo entre su investigación teórica y el trabajo de duelo por la muerte de su padre, Helena Chávez escribe:

Barcelona no logró ser el exilio que buscaba, sino que se convirtió en un lugar de tránsito que me ha permitido habitar entre fantasmas, me ha permitido, en la distancia del espacio, adentrarme en el pasado y ver de frente a los espectros, convocarlos y llamarlos por su nombre.

Este trabajo que comenzó con un enfrentamiento, ha devenido un diálogo que aún no termina, y que permite escuchar la voz de los que ya no están y tanto he querido callar, permite encontrar una voz con la cual hablarles y hablarme. (Chávez, 2006: 78)

Con estas líneas, vínculo tenso entre vivencia y teorización, Helena Chávez abre un diálogo que aún no acaba, pero que tiene una de sus primeras expresiones en su investigación doctoral. En ésta, que a la postre se convertiría en la base del libro que aquí comentamos, madura y reconfigura el concepto de experiencia profundizando en su raigambre kantiana y explorando sus posibilidades desde el horizonte foucaultiano de la semitrascendentalidad y la historicidad, permitiéndole concebir la estética ya no sólo como condición trascendental de posibilidad de la experiencia, ni como una filosofía de lo bello, sino en un sentido constitutivo e histórico 
también de la subjetividad por medio de la afección en múltiples sentidos. Este horizonte le posibilita concebir los procesos de subjetivación desde su radical historicidad y esteticidad, y así le permite también vislumbrar a la estética "como experiencia de la sensibilidad (subjetividad) que irrumpe, removiendo los momentos discursivos y de visibilidades, como campo de fuerzas que hacen de la experiencia estética una política revolucionaria" (Chávez, 2010: 18). En este sentido, lo sensible, lo histórico, lo afectivo y lo político se anudan en este trabajo para poder vislumbrar un posible trastocamiento de la experiencia por medio del arte. En efecto, al comprender la estética como una forma de la política, el arte aparece como una "posibilidad radical para la política como experiencia estética, como experiencia de la sensibilidad que revoluciona producciones e irrumpe como momento fuera de la reflexión [...]" (2010).

Como se puede apreciar, hay un pathos insistente a lo largo de las investigaciones de Chávez Mac Gregor, una especie de obsesión o convicción de que hay algo en el arte, en tanto fenómeno estético/sensible, que es susceptible de posibilitar cambios en la construcción política de las subjetividades. Es una intuición que ha ido depurándose, sofisticándose, consolidándose. Y lo que podemos apreciar a través de esta insistencia es una profunda preocupación por pensar cómo estamos constituidos, construidos, cómo nos relacionamos entre nosotros, cómo podríamos hacerlo de maneras más convenientes.

\section{III}

$\mathrm{Al}$ reconstruir el camino teórico que Helena Chávez Mac Gregor ha recorrido para llegar al libro Insistir en la politica, hemos planteado la mayor parte de los territorios por los cuales discurre esa publicación: la experiencia, la subjetividad, la estética, la política y el arte.

Quizá sea necesario insistir en una última cosa. Previo a la construcción del libro, Helena Chávez vivió un periodo álgido en el que incursionó en prácticas artísticas a través de las cuales realizó exploraciones teóricas en temas como la violencia, el racismo, la biopolítica y la necropolítica. El asunto no es menor. A través del arte, accedió a diferentes formas de conceptualización, teorización y desteorización de estos problemas. No creemos equivocarnos si la mencionamos como una de las voces más lúcidas en la comprensión de la necropolítica en nuestro país, más allá de todo activismo ramplón o moda teórica. Su inmersión en el mundo del arte la llevó a diferentes bienales, a curar exposiciones y a convertirse lentamente en una historiadora del arte con un trasfondo filosófico que no es menor. Pero lo 
crucial está en que esta inmersión le posibilitó una mejor y más amplia comprensión del problema al que se ha enfrentado a lo largo de toda su carrera académica. El problema político que la ha asediado se recrudeció, se especificó, se mostró con todo su pernicioso poder, y al hacerlo no tuvo otro efecto más que el recrudecimiento mismo del pensamiento, el apremio de pensar, de vivir, de hacer.

Insistir en la política, Rancière y la revuelta de la estética es el resultado de este recrudecimiento, de esta necesidad vital; en él encontramos un pensamiento poco ortodoxo, un pensamiento dúctil y experimental que a toda costa busca salidas, que camina por entre los bordes de los conceptos de diferentes autores para obligarlos a pensar el problema que asedia a su autora; encontramos un pensamiento desafiante, denso, estricto y comprometido que busca en las condiciones estéticas de la experiencia las posibilidades para cambiar el rumbo, para no aniquilarnos, para no seguir en la ignominia en la que aún vivimos.

El problema de fondo que sostiene el libro es la certeza de que vivimos "en un tiempo que caracteriza lo político como un trabajo de muerte" (Chávez, 2018: 14). Frente a esta certeza, en el primer capítulo del texto, que funge como introducción y planteamiento del problema, se propone la estética no como una disciplina, sino más como un discurso, o, mejor, como "una trinchera para re-formular la política y renovar desde ella un proceso de emancipación” (2018). En este sentido, uno de los hilos conductores del texto está conformado por el pensamiento de Rancière, con la intención de "proponer desde la revuelta de la estética una posibilidad política que se resiste a la clausura" (2018). Se trata, como hemos dicho, de abrir caminos, de tejer posibilidades, de encontrar "posibles políticos" (2018) que se abren en la relación entre estética y política.

Aunque el libro ofrece un generoso estudio teórico sobre el pensamiento de Rancière, éste no es el centro del libro. De hecho, es difícil hablar de un centro en este libro. Podemos hablar más bien de escenarios problemáticos que se conectan por líneas teóricas transversales que se tensan en diferentes direcciones y que vibran con diferente intensidad en cada escenario. Asuntos como la violencia, la opresión, el autoritarismo, el despojo y la producción de muerte en el mundo contemporáneo son puestos en escena desde la clara conciencia de su dificultad para ser pensados desde el horizonte de la racionalidad política moderna. Así, a través de lo que en el libro se llama "revuelta de la estética" se tensan y ponen en relación los conceptos de estética y política a través de diferentes argumentos, tradiciones y contextos, para mostrar que, a través de lo estético, otra forma de lo político es posible.

En este trayecto, en los capítulos II y III, la autora revisa la lectura que Rancière hace de Kant y de Foucault para poder comprender la estética como el "sistema de las formas que a priori determinan lo que se va a experimentar” (Chávez, 2018: 
63), no como algo originario, ni trascendental en estricto sentido kantiano, sino como "la distribución de lo sensible entendida como el a priori histórico que permite a un estrato un juego específico entre sus visibilidades y enunciaciones" (2018). Este primer hallazgo es fundamental para el texto, pues, por una parte, permite afirmar que "si la estética se relaciona con lo político es porque en la distribución de lo sensible se establecen las visibilidades y enunciaciones que definirán nuestra posición en el común" (2018), y, por otra, porque a través de la afirmación anterior adviene la certeza de que esa distribución de lo sensible es siempre histórica y contingente, es decir, que "estamos inmersos en una formación específica de la episteme que genera ciertas visibilidades y ciertas enunciaciones a través y en las cuales pensamos y nos pensamos" (2018). Con ello, se borra toda posibilidad de asumir la política como algo ontológicamente originario y determinado, y se hace posible, en principio, una forma distinta de re-pensar lo político en su relación con las condiciones estéticas que lo hacen posible.

En este sentido, a partir de los conceptos de desacuerdo, policía e igualdad en el pensamiento de Rancière, la autora examina cómo, según el filósofo francés, es posible pensar la política desde una configuración de lo sensible que nunca es natural ni originaria y que, por ello, es transformable mediante procesos de demostración de la igualdad.

Llegados a este punto, en el capítulo IV, Chávez Mac Gregor emprende una vertiginosa pesquisa para interrogar por el papel del sujeto en esta comprensión de la estética y la política, pues, por una parte, parece imposible proponer una política sin la participación de un sujeto; y, por otra, el concepto mismo de sujeto conlleva cargas históricas y filosóficas de las que el pensamiento de Rancière -y el de la autora misma- intentan desmarcarse. En este sentido, la propuesta teórica del filósofo francés no trata de un sujeto epistémico, ontológico, ético o trascendental, sino de "un sujeto político que, desde su existencia factual, realiza un proceso de subjetivación, es decir, un proceso de enunciación colectiva y anónima que le permite des-identificarse de las lógicas policiales y crear una nueva cuenta en la comunidad que, a su vez, modificará las condiciones de lo sensible" (Chávez, 2018: 122). Decir lo anterior, claro, no es sencillo ni está exento de dificultades, por ello, en este capítulo se tensa la propuesta rancieriana con planteamientos sobre lo político y los procesos de subjetivación derivados de Derrida, Deleuze y Guattari, construyendo un diálogo por demás fructífero para la argumentación.

Finalmente, en el capítulo V, pese a haber advertido en la introducción que el arte jugaría un papel marginal en este trabajo, encontramos la puesta en escena de uno de los trayectos más apasionantes. En él, a partir del caso de la documenta X, curada por Catherine David, se abre la discusión entre el arte y la política, discusión 
en la que tienen lugar diversos autores y artistas, entretejidos por la autora de tal manera que no queda espacio para el maniqueísmo ni la ingenuidad. Tratando de pensar qué es lo que el arte puede dentro de la comprensión de la estética, la política y la subjetividad que se construye a lo largo del libro, la autora reconoce que, pese a que juega un papel importante en la reconfiguración de lo estético y lo político, el arte tiene sus límites, cuyo rebasamiento impulsa él mismo, y, por ello, afirma que

si bien el arte puede llegar a generar ficciones que imaginen los lugares que han sido imposibles por la configuración dominante de lo sensible, es cierto también que procesos artísticos cercanos a la política, es decir, a esas subjetivaciones de identidades imposibles, están actualizando los posibles políticos para forzar su aparición más allá del propio régimen del arte. (Chávez, 2018: 199)

No deja de llamar la atención que la insistencia en el arte, que a lo largo de su trayectoria ha tenido persistencias de intensidades variables, aparezca en este libro paradójicamente insistente. Por una parte, parece haber una gran confianza en su poder re-volucionario, pero, por otra, parece haber una invitación franca a ir más allá de él. Posición comprensible porque, a lo largo de la obra, la importancia capital se centra en lo estético, no en lo artístico.

IV

Finalmente, podemos decir que este libro, más que un texto monográfico sobre Rancière, es problemático, sugerente, que muestra con agudeza los problemas a los que se enfrenta, y que ensaya líneas de fuga a través de diversos posicionamientos teóricos emanados, en su mayoría, de pensadores como Deleuze, Derrida y Rancière, sin que por ello se vuelvan dogma, señalando más bien sus problemas, hiatos y aporías. Tiene, sin duda, lecturas cuestionables, sobre todo si nos posicionamos desde los territorios más clásicos de la filosofía moderna, así como desde ciertas formas de la erudición academicista. Sin embargo, aquí se trata de la presentación de un problema, de su construcción filosófica, y del ensayo de diferentes vías para su esclarecimiento. Se trata, como decíamos atrás, del problema de la experiencia empobrecida y de sus perniciosas consecuencias políticas; se trata de repensar la política desde la estética y de crear una estela que nos permita "imaginar otras escenas, seguir cuestionando las aperturas y transformaciones de lo sensible que la política genera" para "llenarlas de sentido y experiencia” (Chávez, 2018: 200). 
Pensar, decíamos al inicio, es peligroso. Después de todo este recorrido tendríamos que agregar que pensar es también necesario. Helena Chávez Mac Gregor lo sabe a la perfección. Y desde ahí, desde el peligro y la necesidad, pero también desde la alegría y la fuerza que proceden del cuidado de una vida que comienza y que se gestó en su propio cuerpo, nos comparte con generosidad una parte de sus ideas en el libro que aquí reseñamos. Se trata de un libro que ha mesurado y refinado sus conceptos con respecto a su procedencia, pero que ha recrudecido la urgencia vital de pensar, de buscar salidas y crear posibles que nos permitan otro por-venir. 


\section{Bibliografía}

Chávez Mac Gregor, Helena. (2004). La experiencia del arte: Walter Benjamin y el arte de la desconfianza. (Tesis de Licenciatura, Universidad Nacional Autónoma de México). Recuperado de http://132.248.9.195/ppt2004/0330188/ Index.html

Chávez Mac Gregor, Helena. (2006). Lo espectral y la experiencia por-venir. Derrida, lo político y lo estético (Tesis de Maestría, Universitat Autònoma de Barcelona).

Chávez Mac Gregor, Helena. (2010). Entre territorios, estética y política: subjetivación, subjetividad y experiencia revolucionaria (Tesis Doctoral, Universidad Nacional Autónoma de México). Recuperado de http://132.248.9.195/ ptd2010/abril/0657016/Index.html

Chávez Mac Gregor, Helena. (2018). Insistir en la política, Rancière y la revuelta de la estética. México: unam; Instituto de Investigaciones Estéticas. 